\title{
Significados de viver com ferida crônica: estudo de metassíntese
}

\author{
Meanings of living with a chronic wound: a meta-synthesis study
}

Significados de vivir con una herida crónica: estudio de meta-síntesis

Wilkslam Alves de Araújo', Wagner Couto Assis', Alba Benemérita Alves Vilela', Rita Narriman

Silva de Oliveira Boery ${ }^{1}$, Vanda Palmarella Rodrigues ${ }^{1}$, Roseanne Montargil Rocha ${ }^{1, *}$

ORCID IDS

Araújo WA (iD https://orcid.org/0000-0002-3323-4650

Assis WC (D) https://orcid.org/0000-0001-7802-2443

Vilela ABA (D) http://orcid.org/0000-0003-2110-1751

Boery RNSO (D) https://orcid.org/0000-0002-7823-9498

Rodrigues VP (D) https://orcid.org/0000-0002-5689-5910

Rocha RM (D) https://orcid.org/0000-0001-5766-413X

\section{COMO CITAR}

Araújo WA; Assis WC; Vilela ABA, Boery RNSO; Rodrigues VP; Rocha RM. Significados de viver com ferida crônica: estudo de metassíntese. ESTIMA, Braz. J. Enterostomal Ther., 2020, 18: e2420. https://doi. org/10.30886/estima.v18.936_PT

\section{RESUMO}

Objetivo: explorar pesquisas qualitativas sobre os significados de viver com ferida crônica. Método: trata-se de uma metassíntese qualitativa. Foram incluídos 13 artigos, totalizando uma amostra de 248 indivíduos que autorreportaram viver com ferida crônica. Utilizou-se o instrumento do Critical Appraisal Skills Programme para avaliação dos artigos elegíveis, e para relatar a síntese qualitativa, seguiram-se as recomendações do Enhancing transparency in reporting the synthesis of qualitative research. A análise e extração das informações e construção da síntese foram feitas por dois revisores independentes, sob o auxílio de um terceiro revisor especialista. Resultados: viver com ferida crônica envolve preocupações iniciais e aparecimento dos sintomas, especialmente dor marcante. Relatam que o aumento da dor levou à baixa capacidade funcional, bem como relações sociais e condição financeira fragilizadas. As experiências ilustram os desafios da carga emocional e das implicações do adoecimento, que contribuíram para o isolamento social. A religiosidade e espiritualidade foram as principais estratégias de enfrentamento. Conclusão: viver com ferida crônica significa uma condição de dor, limita a capacidade física e funcional, provoca sentimentos e emoções negativas que resultam no isolamento das pessoas.

DESCRITORES: Emoções; Estomaterapia; Ferimentos e lesões; Percepção; Acontecimentos que mudam a vida; Pesquisa qualitativa.

1. Universidade Estadual do Sudoeste da Bahia - Programa de Pós-graduação em Enfermagem e Saúde - Jequié (BA), Brasil.

*Autora correspondente: wilkslam@hotmail.com

Recebido: Ago. 10, 2020 | Aceito: Out. 06, 2020 
ABSTRACT

Objective: explore qualitative research on the meanings of living with a chronic wound. Method: it is a qualitative meta-synthesis. 13 articles were included, totaling a sample of 248 individuals who self-reported living with a chronic wound. The Critical Appraisal Skills Program instrument was used to evaluate the eligible articles, and to report the qualitative synthesis, the recommendations of Enhancing transparency in reporting the synthesis of qualitative research were followed. The analysis and extraction of information and construction of the synthesis were carried out by two independent reviewers, with the assistance of a third expert reviewer. Results: living with a chronic wound involves initial concerns and the appearance of symptoms, especially marked pain. They report that the increase in pain led to low functional capacity, as well as weakened social relationships and financial conditions. The experiences illustrate the challenges of emotional burden and the implications of illness, which contributed to social isolation. Religiosity and spirituality were the main coping strategies. Conclusion: living with a chronic wound means a condition of pain, limits physical and functional capacity, causes negative feelings and emotions that result in people's isolation.

DESCRIPTORS: Emotions; Stomatherapy; Wounds and injuries; Perception; Life-changing events; Qualitative research.

\section{RESUMEN}

Objetivo: explorar la investigación cualitativa sobre los significados de vivir con una herida crónica. Método: se trata de una metasíntesis cualitativa. Se incluyeron 13 artículos, totalizando una muestra de 248 individuos que declararon vivir con una herida crónica. Se utilizó el instrumento Critical Evaluation Skills Programme (CASP) para evaluar los artículos elegibles y reportar la síntesis cualitativa, siguiendo las recomendaciones de la Mejora de la transparencia en el reporte de la síntesis de la investigación cualitativa (ENTREQ). El análisis y la extracción de información y la construcción de la síntesis fueron realizados por dos revisores independientes, con la asistencia de un tercer revisor experto. Resultados: convivir con una herida crónica implica preocupaciones iniciales y la aparición de síntomas, especialmente dolor marcado. Informan que el aumento del dolor llevó a una baja capacidad funcional, así como al debilitamiento de las relaciones sociales y las condiciones financieras. Las experiencias ilustran los desafíos de la carga emocional y las implicaciones de enfermarse, lo que contribuyó al aislamiento social. La religiosidad y la espiritualidad fueron las principales estrategias de afrontamiento. Conclusión: vivir con una herida crónica significa una condición de dolor, limita la capacidad física y funcional, provoca sentimientos y emociones negativas que resultan en el aislamiento de las personas.

DESCRIPTORES: Emociones; Enfermeira; Heridasy Traumatismos; Percepción; Acontecimientos que Cambian la Vida; Investigación Cualitativa.

\section{INTRODUÇÃO}

A ferida crônica é uma ruptura na estrutura tegumentar com alterações anatômicas e fisiológicas associadas ao processo de cura prolongado, que pode acometer indivíduos de todas as idades e causar impactos negativos na vida cotidiana da pessoa devido ao seu potencial em provocar alterações na integridade da pele, prurido, dor, exsudato e odor ${ }^{1,2}$. Além disso, ocasiona mudanças diretas no estilo de vida, na carreira profissional e na imagem corporal, constituindo-se em um grave problema para o sistema de saúde ${ }^{3,4}$.

Entre os sintomas, a dor foi o mais relatado pelas pessoas que vivenciam a existência da ferida crônica, sendo agravada pelo curso prolongado de cura e ameaça de recorrência da lesão $0^{5}$. A ferida dolorosa acaba influenciando nas atividades diárias, no trabalho e lazer, o que faz contribuir para baixa capacidade funcional, sono insatisfatório, instabilidade emocional, sofrimento, desesperança e depressão $0^{6,7}$. Nesse contexto, a experiência de viver com uma ferida crônica ainda manifesta sentimentos de preocupação, culpa, alteração de humor, frustração, decepção, ansiedade, medo e tristeza ${ }^{8,9}$.
Outros fatores comuns são as alterações na relação com seus familiares, no convívio social e aumento do isolamento social. Além desses sentimentos, o estado de cronicidade leva a pessoa a sentir vergonha de mostrar seu corpo ferido a outras pessoas do seu convívio social 5 .

Embora as pessoas feridas desejem alívio e controle dos sintomas, principalmente a dor, elas geralmente, no início do adoecimento, negam a existência da ferida e mais tarde chegam a um momento em que aceitam a condição crônica como uma característica inerente ao seu corpo para o resto de suas vidas ${ }^{10}$. Esse tem sido um fato frequentemente citado, portanto, cuidar de pessoas com feridas crônicas é um dos desafios para a enfermagem e que precisa de maior compreensão da dimensão existencial do indivíduo ${ }^{11,12}$.

Encontraram-se somente três sínteses publicadas da pesquisa qualitativa explorando a experiência de viver com ferida crônica, duas voltadas para pessoas com úlcera na perna $^{13,14}$, e a outra, mais abrangente, incluindo todos os tipos de feridas crônicas, porém apresenta limitações no seu percurso metodológico ${ }^{15}$. A síntese qualitativa envolve a comparação e discussão dos resultados de cada estudo 
qualitativo, com o intuito de gerar novas interpretações em torno de um tema comum ${ }^{16}$. Portanto, ainda é necessário produzir esse tipo de estudo para aumentar a compreensão dos significados que carregam essas pessoas e para que se possa fornecer mais informações que visem aprimoramento e desenvolvimento de condutas de enfermagem que facilitem o processo de cicatrização e promoção de melhores condições de vida ${ }^{1,11}$.

\section{OBJETIVO}

Explorar pesquisas qualitativas sobre os significados de viver com ferida crônica.

\section{MÉTODO}

Trata-se de uma metassíntese qualitativa, fundamentada nas seguintes etapas propostas por Sandelowski e Barroso ${ }^{17}$ : elaboração da pergunta de pesquisa e problema; definição das fontes de busca de dados e seleção dos artigos; avaliação e análise dos artigos; extração dos dados e construção da síntese. O processo metodológico foi guiado pela pergunta formulada através da estratégia $\mathrm{PICO}^{18}$ : como é viver com ferida crônica na perspectiva da pessoa acometida por essas lesões?

Realizou-se a busca ampla e exaustiva da literatura, com o intuito de identificar todos os artigos que utilizaram método qualitativo para descrever os significados de viver com ferida crônica na perspectiva da pessoa acometida. A busca foi conduzida por dois revisores independentes (WAA e WAC), nas bases de dados multidisciplinares CINAHL, LILACS, PubMed, Scopus e Web of Science. Os descritores e palavras-chave foram definidos de acordo com o tema desta revisão em três abrangentes categorias: 1) sentimentos ("emoções", "emoções manifestas", "ansiedade", "medo", “culpa”, "esperança”, "solidão”, "luto”, "tédio”, "percepção”); 2) ferida crônica ("ferimentos e lesões", "úlcera cutânea", "úlcera da perna", "úlcera venosa", "ferida crônica", "curativos"); e 3) estudos qualitativos ("pesquisa qualitativa", "antropologia", "etnografia”, "hermenêutica", "fenomenologia", "experiência vivida", "teoria fundamentada"). Os cruzamentos entre os descritores e palavras-chave foram refinados e combinados com o operador "AND" durante o processo de busca, de acordo com cada base de dados.
Foram incluídos artigos primários disponíveis nos idiomas inglês, português e espanhol, que utilizaram método e plano de análise de cunho qualitativo, publicados no período de 2014 a junho de 2019, com indivíduos do sexo masculino e feminino (idade $\geq 18$ anos), que autorreportaram viver com ferida crônica. Estipulou-se por excluir revisões de literatura, artigos duplicados, estudos que abordassem queimaduras, como também as que discutissem a vivência da pessoa com ferida crônica na perspectiva de familiares, cuidadores, amigos ou dos profissionais de saúde. A busca nas bases de dados ocorreu em junho de 2019.

A Fig. 1 ilustra o processo de busca na literatura e inclusão dos estudos, conforme as recomendações PRISMA ${ }^{19}$. O total dos resultados obtidos foi de 2.158 artigos, dos quais 137 eram duplicações, que após serem removidas apurou-se o total de 938 artigos. Em seguida, dois revisores (WAA e WAC) procederam com a leitura dos títulos e resumos dos artigos triados e fizeram os seus julgamentos em duas etapas, a primeira de maneira independente e em um segundo momento juntos, eliminando os artigos que não atenderam aos critérios de elegibilidade. Como resultado desse procedimento, 30 artigos cumpriram esses critérios. Realizou-se, então, o cálculo de Kapp ${ }^{20}$, para avaliar o nível de concordância entre observadores e o resultado obtido indicou 0.857 - representando concordância excelente. Logo após, os revisores realizaram leitura independente dos 30 artigos elegíveis, e com auxílio de um terceiro revisor (RMR), com expertise em pesquisa qualitativa e na temática deste artigo, determinaram a elegibilidade final dos artigos. Depois dessa etapa excluíram 17 artigos por causa do método de pesquisa $(n=3)$, considerando que esses artigos focavam na experiência vivenciada em relação ao método terapêutico de cuidado ( $n=11)$, em razão de se tratar de pessoas com ferida cicatrizada, mas que sofriam ameaça elevada de recorrência ( $n=1)$, e por abordarem o contexto de lesões traumáticas $(\mathrm{n}=1)$, como também ferida cirúrgica por segunda intenção $(n=1)$, resultando em uma amostra final de 13 artigos.

Salienta-se que foram incluídos na amostra artigos que reportavam a percepção da pessoa acometida por ferida crônica e do cuidador ${ }^{21}$, pois os resultados relativos ao participante lesionado estavam apresentados separadamente aos do cuidador. Da mesma forma, seguiram-se para os estudos que apresentavam indivíduos com ferida crônica curada ${ }^{7,22}$ ou que envolviam úlcera de pé diabético e amputação de membros inferiores em uma mesma amostra ${ }^{23}$. 


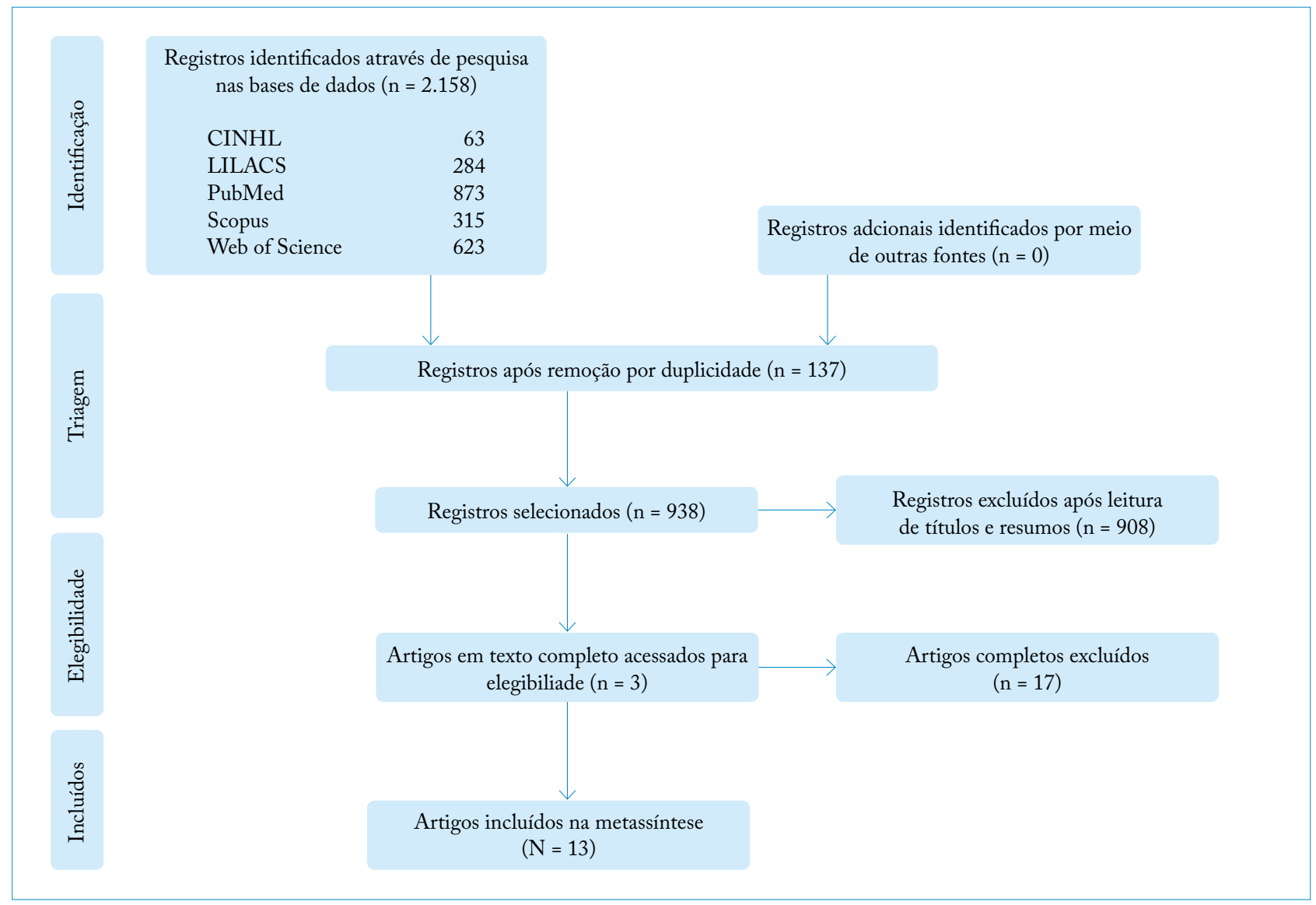

Figura 1. Fluxograma PRISMA do processo de busca na literatura19. Jequié (BA), Brasil - 2019.

A avaliação da qualidade dos estudos na revisão foi verificada por meio das ferramentas do Critical Appraisal Skills Programme (CASP), que disponibiliza um instrumento padronizado para avaliar o rigor dos estudos qualitativos ${ }^{24} . \mathrm{Em}$ relação aos procedimentos para relatar a síntese qualitativa, seguiram-se as recomendações descritas no Enhancing transparency in reporting the synthesis of qualitative research (ENTREQ $)^{25}$.

No processo de produção e interpretação dos dados (extração e síntese), ambos os revisores realizaram leituras sucessivas independentes dos textos completos que compuseram a amostra final ( $\mathrm{n}=13)$, dos quais extraíram as informações dos artigos. Em atenção à pergunta de pesquisa, os dados foram sistematizados em formulário eletrônico padronizado. O formulário foi construído coletivamente e acordado pela equipe de pesquisa. Foram extraídas informações sobre autoria, ano, país, tipo de ferida do estudo, participantes da pesquisa, produção de dados e plano de análise através da leitura e avaliação dos artigos. Após, em conjunto, os revisores (WAA e WAC) reavaliaram todas as informações extraídas, obtendo-se consenso sobre divergências na avaliação primária. A extração das informações foi encerrada quando os revisores (WAA e WAC) concordaram que haviam chegado à condição de saturação dos dados, sem acrescer conhecimento novo, ou seja, sem construção de novos temas.

Simultaneamente ao processo de extração das informações, realizou-se a codificação, de maneira independente, em caráter indutivo para elaborar as categorias temáticas relativas aos significados de se conviver com ferida crônica, de modo a facilitar a síntese dos dados. A codificação dos resultados dos artigos foi orientada pela análise temática, composta pelas seguintes etapas: familiarização dos dados; gerar os códigos iniciais; explorar a busca por temas; revisar os temas elencados; definir e nomear os temas; e produzir o relatório final ${ }^{26}$.

Subsequentemente, os revisores reuniram-se para verificar, discutir e interpretar criticamente os códigos e temas, bem como os conceitos referentes às categorias geradas, para resolver algum conflito, sob o auxílio do terceiro revisor (RMR), especialista em tratamento de feridas. As instruções para análise foram seguidas da forma mais fiel possível pela equipe do estudo, que incluiu dois enfermeiros 
(RMR e WAA) e um dentista (WAC), que juntos a mais três enfermeiras externas (ABAV, RNSOB e VPR) discutiram e examinaram a relevância clínica dos temas emergentes e conclusões das evidências científicas. Dessa forma, foi possível uma nova interpretação para os resultados oriundos dos estudos primários.

\section{RESULTADOS}

Os estudos incluídos na análise ( $\mathrm{n}=13)$ foram realizados no Brasil ( $\mathrm{n}=5$ ), Estados Unidos ( $\mathrm{n}=2$ ), Reino Unido ( $\mathrm{n}=1$ ), Austrália ( $n=2)$, Dinamarca $(n=1)$, Itália $(n=1)$ e Suécia $(\mathrm{n}=1)$, conforme descrito na Tabela 1 . Os 13 artigos ${ }^{7,21-23,27-35}$ incluíram o total de 248 participantes, a maioria do sexo feminino ( $n=145)$, com faixa etária entre 27 e 95 anos de idade e de diferentes etnias, que vivenciaram a condição de serem acometidos por úlcera venosa ${ }^{27,29,33}$, feridas crônicas diversas ${ }^{7,28}$, úlceras de perna ${ }^{22,30-32,35}$, lesão por pressão $0^{21}$, pé diabético ${ }^{34}$, como também houveram indivíduos com amputação de membros inferiores compondo a amostra do mesmo estudo ${ }^{23}$.

Vários delineamentos qualitativos foram usados para a produção de dados, incluindo entrevistas semiestruturadas $^{21-23,27,29-32,34,35}$, entrevista fenomenológica ${ }^{33}$, entrevista em profundidade ${ }^{7,28}$, desenho-estória tema ${ }^{28} \mathrm{e}$ entrevista em grupo focal ${ }^{32}$. O plano de análise teórico que sustentou o desenvolvimento dos estudos foi guiado pelos pressupostos da análise de conteúdo temática ${ }^{7,21,22,27-30,34}$, abordagem integrada para codificação e análise dos dados por meio do desenvolvimento de taxonomia, temas e teoria ${ }^{23}$, teoria fundamentada nos dados ${ }^{31}$, plano fenomenológico ${ }^{33}$, método hermenêutico ${ }^{32}$ e condensação sistemática de texto ${ }^{35}$.

Em geral, os estudos qualitativos foram considerados de boa qualidade, conforme apresentados na Tabela 2. A maioria dos estudos ${ }^{7,21-23,29-32,34}$ ( $n=9$ ) foi julgada como reportando devidamente todas as questões do checklist $\mathrm{CASP}^{24}$. Em três estudos ${ }^{27,28,35}$ as informações relativas à estratégia de recrutamento utilizada não foram reportadas de forma adequada e, ainda na mesma questão, um outro estudo não descreveu o recrutamento dos participantes ${ }^{33}$. No estudo ${ }^{27}$, as informações da coleta de dados foram parcialmente reportadas e a análise dos dados foi insuficientemente rigorosa, como também a relação entre o pesquisador e os participantes não foi considerada.

Os resultados provenientes da extração e síntese dos estudos sobre as experiências de pessoas que vivem com ferida crônica foram explorados e possibilitaram a construção de três temas principais, por meio da metassíntese: 1) preocupações iniciais e aparecimento dos sintomas; 2) sentimentos, emoções e enfrentamentos cotidianos; 3) desenvolvimento de desejos e estratégias de enfrentamento. Esses temas estão apresentados na Tabela 3 e mostram os significados da experiência de viver com ferida crônica na perspectiva da pessoa acometida.

Tabela 1. Características dos estudos primários incluídos na metassíntese. Jequié (BA), Brasil - 2019.

\begin{tabular}{|c|c|c|c|c|c|}
\hline $\begin{array}{l}\text { Autor, } \\
\text { ano }\end{array}$ & País & $\begin{array}{l}\text { Tipo de } \\
\text { ferida }\end{array}$ & Participantes & $\begin{array}{l}\text { Produção } \\
\text { de dados }\end{array}$ & $\begin{array}{l}\text { Plano de } \\
\text { análise }\end{array}$ \\
\hline $\begin{array}{l}\text { Aguiar, } \\
2014^{27}\end{array}$ & Brasil & $\begin{array}{l}\text { Úlcera } \\
\text { venosa }\end{array}$ & $\begin{array}{l}\text { Amostra ( } n=10) \text { : nenhum detalhe } \\
\text { da amostra é informado. }\end{array}$ & $\begin{array}{c}\text { Entrevistas } \\
\text { semiestruturadas }\end{array}$ & $\begin{array}{l}\text { Análise de conteúdo } \\
\text { temática de Bardin }\end{array}$ \\
\hline $\begin{array}{l}\text { Alves, } \\
2014^{28}\end{array}$ & Brasil & $\begin{array}{l}\text { Feridas } \\
\text { crônicas }\end{array}$ & $\begin{array}{l}\text { Amostra (n=45): estudo com mulheres. } \\
\text { Faixa etária: } 29-88 \text { anos; não informa a } \\
\text { média de idade. }\end{array}$ & $\begin{array}{l}\text { Desenho-estória } \\
\text { tema e entrevista } \\
\text { em profundidade }\end{array}$ & $\begin{array}{l}\text { Análise de conteúdo dos } \\
\text { desenhos-estórias tema } \\
\text { proposto por Coutinho } \\
\text { e a análise de conteúdo } \\
\text { temática de Minayo }\end{array}$ \\
\hline $\begin{array}{l}\text { Alves, } \\
2015^{29}\end{array}$ & Brasil & $\begin{array}{l}\text { Úlcera } \\
\text { venosa }\end{array}$ & $\begin{array}{l}\text { Amostra ( } \mathrm{n}=8) \text { : } 4 \text { homens, } 4 \text { mulheres. } \\
\text { Faixa etária: houve prevalência entre } \\
\text { 60-80 anos ( } \mathrm{n}=5) \text {, a idade dos demais } \\
\text { participantes não foi informada; } \\
\text { como também a média de idade } \\
\text { não estava descrita. }\end{array}$ & $\begin{array}{c}\text { Entrevista } \\
\text { estruturada }\end{array}$ & $\begin{array}{l}\text { Análise de conteúdo } \\
\text { temática de Bardin }\end{array}$ \\
\hline
\end{tabular}


Tabela 1. Continuação...

\begin{tabular}{|c|c|c|c|c|c|}
\hline $\begin{array}{l}\text { Autor, } \\
\text { ano }\end{array}$ & País & $\begin{array}{l}\text { Tipo de } \\
\text { ferida }\end{array}$ & Participantes & $\begin{array}{l}\text { Produção } \\
\text { de dados }\end{array}$ & $\begin{array}{l}\text { Plano de } \\
\text { análise }\end{array}$ \\
\hline $\begin{array}{l}\text { Buso, } \\
2016^{30}\end{array}$ & Brasil & $\begin{array}{l}\text { Úlceras de } \\
\text { perna }\end{array}$ & $\begin{array}{l}\text { Amostra ( } n=7) \text { : } 3 \text { homens, } \\
\qquad 4 \text { mulheres. } \\
\text { Faixa etária: } 65-86 \text { anos; não informa } \\
\text { a média de idade. }\end{array}$ & $\begin{array}{c}\text { Entrevistas } \\
\text { semiestruturadas }\end{array}$ & $\begin{array}{l}\text { Análise de conteúdo } \\
\text { temática de Minayo }\end{array}$ \\
\hline $\begin{array}{l}\text { Barg, } \\
2017^{23}\end{array}$ & $\begin{array}{l}\text { Estados } \\
\text { Unidos da } \\
\text { América }\end{array}$ & $\begin{array}{c}\text { Pé } \\
\text { diabético } \\
\text { ou } \\
\text { amputação } \\
\text { de } \\
\text { membros } \\
\text { inferiores }\end{array}$ & $\begin{array}{l}\text { Amostra (n=39): } 24 \text { homens, } \\
15 \text { mulheres. } \\
\text { Faixa etária: não informa; porém, a } \\
\text { idade média foi de } 60,9 \text { anos } \\
\text { (DP: 13,9). }\end{array}$ & $\begin{array}{c}\text { Entrevistas } \\
\text { semiestruturadas }\end{array}$ & $\begin{array}{l}\text { Abordagem integrada } \\
\text { para codificação e } \\
\text { análise dos dados: } \\
\text { desenvolvimento de } \\
\text { taxonomia, temas e } \\
\text { teoria }\end{array}$ \\
\hline $\begin{array}{l}\text { Cipolletta, } \\
2017^{31}\end{array}$ & Itália & $\begin{array}{l}\text { Úlceras de } \\
\text { perna }\end{array}$ & $\begin{array}{l}\text { Amostra ( } \mathrm{n}=21) \text { : } 9 \text { homens, } \\
\qquad 12 \text { mulheres. } \\
\text { Faixa etária: } 27-78 \text { anos; } \\
\text { com idade média de } 55 \text { anos. }\end{array}$ & $\begin{array}{c}\text { Entrevistas } \\
\text { semiestruturadas }\end{array}$ & $\begin{array}{c}\text { Teoria fundamentada } \\
\text { nos dados }\end{array}$ \\
\hline $\begin{array}{l}\text { Lernevall, } \\
2017^{32}\end{array}$ & Dinamarca & $\begin{array}{l}\text { Úlceras de } \\
\text { perna }\end{array}$ & $\begin{array}{l}\text { Amostra ( } \mathrm{n}=6) \text { : } 4 \text { homens, } \\
22 \text { mulheres. } \\
\text { Faixa etária: } 61-77 \text { anos; com idade } \\
\text { média de } 69,1 \text { anos. }\end{array}$ & $\begin{array}{l}\text { Entrevista em } \\
\text { grupo focal }(n=4) \\
\text { e entrevistas } \\
\text { semiestruturadas } \\
\qquad(n=5)\end{array}$ & $\begin{array}{c}\text { Método hermenêutico } \\
\text { de Ricoeur }\end{array}$ \\
\hline $\begin{array}{l}\text { Umeh, } \\
2017^{22}\end{array}$ & $\begin{array}{l}\text { Estados } \\
\text { Unidos da } \\
\text { América }\end{array}$ & $\begin{array}{l}\text { Úlceras de } \\
\text { perna }\end{array}$ & $\begin{array}{l}\text { Amostra ( } \mathrm{n}=20): 9 \text { homens, } \\
11 \text { mulheres. } \\
\text { Faixa etária: } 29-63 \text { anos; } \\
\text { com idade média de 42,4 anos. } \\
\text { Observação: dois participantes } \\
\text { tinham ulceras cicatrizadas. }\end{array}$ & $\begin{array}{c}\text { Entrevistas } \\
\text { semiestruturadas }\end{array}$ & Análise temática \\
\hline $\begin{array}{l}\text { Jackson, } \\
2018^{21}\end{array}$ & $\begin{array}{l}\text { Reino } \\
\text { Unido }\end{array}$ & $\begin{array}{l}\text { Lesão por } \\
\text { pressão }\end{array}$ & $\begin{array}{l}\text { Amostra ( } \mathrm{n}=12) \text { : } 3 \text { homens, } \\
9 \text { mulheres. } \\
\text { Faixa etária: 31-92 anos; não informa } \\
\text { a média de idade. }\end{array}$ & $\begin{array}{c}\text { Entrevistas } \\
\text { semiestruturadas }\end{array}$ & $\begin{array}{c}\text { Análise temática } \\
\text { estabelecida por Braun } \\
\text { e Clarke }\end{array}$ \\
\hline $\begin{array}{l}\text { Joaquim, } \\
2018^{33}\end{array}$ & Brasil & $\begin{array}{l}\text { Úlcera } \\
\text { venosa }\end{array}$ & $\begin{array}{l}\text { Amostra ( } \mathrm{n=36} \text { ): } 16 \text { homens, } \\
20 \text { mulheres. } \\
\text { Faixa etária: } 41-84 \text { anos; } \\
\text { com idade média de 65,3 anos. }\end{array}$ & $\begin{array}{c}\text { Entrevista } \\
\text { fenomenológica }\end{array}$ & $\begin{array}{c}\text { Fenomenológico } \\
\text { descritivo na perspectiva } \\
\text { Merleau-Pontiana }\end{array}$ \\
\hline $\begin{array}{l}\text { Kapp, } \\
2018^{7}\end{array}$ & Austrália & $\begin{array}{l}\text { Feridas } \\
\text { crônicas }\end{array}$ & $\begin{array}{l}\text { Amostra ( } \mathrm{n}=25) \text { : } 12 \text { homens, } \\
13 \text { mulheres. } \\
\text { Faixa etária: } 52-95 \text { anos; com idade } \\
\text { média de } 71 \text { anos }\end{array}$ & $\begin{array}{l}\text { Entrevista em } \\
\text { profundidade }\end{array}$ & $\begin{array}{c}\text { Análise temática } \\
\text { estabelecida por Braun } \\
\text { e Clarke }\end{array}$ \\
\hline $\begin{array}{l}\text { Palaya, } \\
2018^{34}\end{array}$ & Austrália & $\begin{array}{c}\text { Pé } \\
\text { diabético }\end{array}$ & $\begin{array}{l}\text { Amostra ( } \mathrm{n}=8 \text { ): } 4 \text { homens, } \\
4 \text { mulheres. } \\
\text { Faixa etária: } 48-74 \text { anos; com idade } \\
\text { média de } 63,2 \text { anos. }\end{array}$ & $\begin{array}{c}\text { Entrevistas } \\
\text { semiestruturadas }\end{array}$ & Análise temática \\
\hline $\begin{array}{l}\text { Marczak, } \\
2019^{35}\end{array}$ & Suécia & $\begin{array}{l}\text { Úlceras de } \\
\text { perna }\end{array}$ & $\begin{array}{l}\text { Amostra ( } \mathrm{n}=11) \text { : } 5 \text { homens, } \\
\qquad 6 \text { mulheres. } \\
\text { Faixa etária: } 27-83 \text { anos, com idade } \\
\text { média de } 62,5 \text { anos. }\end{array}$ & $\begin{array}{c}\text { Entrevistas } \\
\text { semiestruturadas }\end{array}$ & $\begin{array}{c}\text { Condensação sistemática } \\
\text { de texto por Malterud }\end{array}$ \\
\hline
\end{tabular}

DP = desvio padrão. 
Tabela 2. Avaliação da qualidade dos estudos incluídos a partir do Critical Appraisal Skills Programme. Jequié (BA), Brasil - 2019.

\begin{tabular}{|c|c|c|c|}
\hline Questão & $\operatorname{Sim}^{*}$ & $\begin{array}{c}\text { Parcialmente } \\
\text { reportado* }\end{array}$ & Não* \\
\hline 1. Os objetivos da pesquisa estavam reportados claramente? & 13 & 0 & 0 \\
\hline 2. A metodologia qualitativa é adequada? & 13 & 0 & 0 \\
\hline 3. O desenho da pesquisa estava adequado para alcance dos objetivos propostos? & 13 & 0 & 0 \\
\hline 4. A estratégia de recrutamento foi adequada aos objetivos da pesquisa? & 9 & $3^{27-28,35}$ & 133 \\
\hline 5. Os dados foram coletados de modo que abordassem a questão de pesquisa? & 12 & 127 & 0 \\
\hline 6. A relação entre o pesquisador e os participantes foi devidamente considerada? & 12 & 0 & 127 \\
\hline 7. As questões éticas foram consideradas? & 13 & 0 & 0 \\
\hline 8. A análise dos dados foi suficientemente rigorosa? & 12 & 127 & 0 \\
\hline 9. Os resultados foram reportados claramente? & 13 & 0 & 0 \\
\hline 10. A pesquisa traz contribuições? & 13 & 0 & 0 \\
\hline
\end{tabular}

*Número de estudos.

Tabela 3. Temas e síntese do conhecimento dos estudos. Jequié (BA), Brasil - 2019.

\begin{tabular}{|c|c|c|}
\hline Temas & & Síntese do conhecimento \\
\hline & $\begin{array}{l}\text { Característica } \\
\text { marcante: dor }\end{array}$ & $\begin{array}{l}\text { De modo inicial, há o aparecimento de pequenas lesões que parecem não incomodar. } \\
\text { Porém mais tardiamente provocam dor insuportável, queimação no local da ferida, } \\
\text { coceira, inchaço e desconforto na pessoa acometida por ferida crônica }\end{array}$ \\
\hline $\begin{array}{l}\text { Preocupações iniciais } \\
\text { e aparecimento dos } \\
\text { sintomas }\end{array}$ & $\begin{array}{l}\text { Aceitação e } \\
\text { decisão de } \\
\text { procurar os } \\
\text { serviços de saúde }\end{array}$ & $\begin{array}{l}\text { Inicialmente, apresentam sentimento de autoeficácia que se associa ao aumento } \\
\text { dos sintomas (área da lesão, dor, secreções e odores). Ainda no começo existe a } \\
\text { necessidade de buscar informações, principalmente na internet, sobre a ferida, } \\
\text { bem como pode ocorrer a utilização de preparações caseiras até o momento que } \\
\text { o indivíduo observa a cronicidade da ferida. Posteriormente, com falta de cura, os } \\
\text { sujeitos acabam aceitando a condição do adoecimento, que logo recebem incentivo da } \\
\text { rede de apoio (amigos ou parentes) para procurar o serviço de saúde } 7,22,30-31,35\end{array}$ \\
\hline \multirow[t]{2}{*}{$\begin{array}{l}\text { Sentimentos, } \\
\text { emoções e } \\
\text { enfrentamento } \\
\text { cotidiano }\end{array}$} & $\begin{array}{l}\text { Mudança } \\
\text { na relação } \\
\text { sociocultural, } \\
\text { familiar e } \\
\text { econômica }\end{array}$ & $\begin{array}{l}\text { (a) Limitação física: aumento da dor levou a diminuição da mobilidade, } \\
\text { especialmente das atividades cotidianas e de lazer. (b) Relações sociais e rede de } \\
\text { apoio: a curiosidade frente à pessoa com ferida desencadeia relações sociais } \\
\text { fragilizadas. Há um esforço de esconder a ferida por vergonha e para evitar } \\
\text { questionamentos. Em geral, a pessoa adoecida sente-se um fardo ou dependente } \\
\text { do cuidador da sua rede de apoio. (c) Condição financeira: improdutividade ou } \\
\text { apresenta incapacidade de trabalhar, como também foram observadas queixas } \\
\text { constantes de custos elevados dos remédios. (d) Sono, repouso e sexualidade: } \\
\text { dificuldade para dormir e descansar; sexualidade prejudicada decorrente da } \\
\text { necessidade constante de esclarecimento para o novo parceiro; e perda da } \\
\text { privacidade associada à exigência de cuidados íntimos. Todos esses fatores } \\
\text { contribuíram para o (e) isolamento social em virtude da carga emocional e das } \\
\text { implicações de viver com uma ferida crônicat,21-23,27-35 }\end{array}$ \\
\hline & $\begin{array}{c}\text { Manifestações } \\
\text { envolvidas }\end{array}$ & $\begin{array}{l}\text { Preocupações, dor, perda da esperança de cura, diminuição do humor, choro, } \\
\text { incapacidade, angústia, medo, raiva, culpa, incômodo, vergonha, insegurança, } \\
\text { sentir-se inútil para a vida, estresse, sofrimento, ansiedade, depressão, tentativa de } \\
\text { suicídio e luto antecipado são resultantes da condição de adoecimento em relação } \\
\text { à ferida crônica, }\end{array}$ \\
\hline $\begin{array}{l}\text { Desenvolvimento } \\
\text { de desejos e } \\
\text { espiritualidade } \\
\text { como estratégia de } \\
\text { enfrentamento }\end{array}$ & $\begin{array}{c}\text { Métodos de } \\
\text { enfrentamento }\end{array}$ & $\begin{array}{l}\text { (a) Estratégias: aceitar a condição da ferida crônica e a continuidade do apoio da rede } \\
\text { (parentes e profissionais) apresentaram-se como estratégias positivas. Em geral, } \\
\text { assistir à televisão foi a principal atividade de lazer. E a religiosidade serviu como } \\
\text { uma fonte de força e esperança, especialmente quando o apoio familiar era ausente. } \\
\text { (b) Desejos: fornecer apoio e informação sobre a experiência de viver com feridas } \\
\text { crônicas para outras pessoas que vivenciam o adoecimento recente, e desejo por } \\
\text { novas pesquisas para investigar formas terapêuticas de cura da ferida } 22,27,29,35\end{array}$ \\
\hline
\end{tabular}




\section{DISCUSSÃO}

Este estudo mostra que viver com uma ferida crônica é um processo contínuo que envolve preocupações iniciais, dor, aceitação do estado de cronicidade, limitações cotidianas e no estilo de vida, manifestações diversas de sentimentos, emoções, estratégias de enfrentamento e desejos que podem fortalecer a vontade de procurar ajuda de assistência de cuidados à saúde. Cada tema e síntese de conhecimento são discutidos a seguir.

\section{Preocupações iniciais e aparecimento dos sintomas}

Esse tema representou as preocupações iniciais da pessoa com ferida crônica em relação ao surgimento da ferida e aparecimento dos primeiros sintomas, especialmente sobre a característica marcante da dor, da aceitação inicial da condição de adoecimento e decisão de procurar os serviços de saúde motivados pela sua rede de apoio. A experiência de viver diariamente com dor foi um significado frequentemente atribuído pelas pessoas com ferida crônica ${ }^{7,21-23,27-35}$. Estudos anteriore ${ }^{32,36-38}$ mostraram que o sintoma de dor é o mais comumente relatado pelos entrevistados, seguido de secreções, odores, desconforto, ansiedade e depressão, o que está de acordo com os achados desta metassíntese.

O estudo de Marczak et al. ${ }^{35}$ demonstrou que todos os entrevistados estavam inicialmente despreocupados com a presença da ferida crônica, que em sua maioria optou por realizar autotratamento com preparações caseiras, conforme suas próprias experiências ou aguardou melhorias, porém diante do processo de não cura da ferida, eles começaram a se questionar e a buscar informações na internet e com sua rede de apoio (familiares, amigos e colegas de trabalho). Ou seja, viu-se que quanto mais tempo a ferida demorava a cicatrizar, mais preocupadas e ansiosas ficavam as pessoas. Essa fase é vivenciada com dubiedade de significados, sendo mais evidente em pessoas idosas ${ }^{35}$.

A dor ocasionada pela ferida crônica foi destaque em todos os estudos que compuseram esta metassíntese, sendo descrita como contínua e com sensação de alívio imprevisível ${ }^{7,22}$. Além da dor, as pessoas disseram sentir queimação e prurido no local da ferida, que com o passar das semanas parecia deixá-las limitadas, impotentes, frustradas e com interferência nos domínios da qualidade de vida, que consequentemente resultou no isolamento social ${ }^{28,35}$. A dor aumentou progressivamente em relação ao tempo de não cura da ferida, se tornou insuportável e acabou ganhando destaque central na vida das pessoas ${ }^{22,34}$.

Dessa maneira, os estudos ${ }^{22,28,35}$ apontam que viver ferido em um estado de cronicidade significa afetar as atividades cotidianas das pessoas e ter pensamentos negativos sobre a ferida dolorosa, sendo que alguns indivíduos são mais afetados que outros. Nos participantes mais jovens, a dor teve forte impacto nas atividades de trabalho e lazer ${ }^{35}$.Já o isolamento social foi maior na faixa etária mais avançada ${ }^{35}$. Com a significação e presença da dor, desconforto e pensamentos negativos concentrados na ferida era difícil para as pessoas conseguirem descansar ou dormir ${ }^{7,35}$. A redução da qualidade do sono também foi observada em outros estudos $28,29,33$.

\section{Sentimentos, emoções e enfrentamentos cotidianos}

A ferida dolorosa pode significar mudanças na relação sociocultural, familiar e econômica das pessoas e gerar diferentes manifestações de sentimentos e emoções. Entre as principais mudanças, destacam-se a limitação física, relações sociais e rede de apoio, condição financeira, sono, repouso, sexualidade e isolamento social. As mudanças ocorreram principalmente pelo significado de presença da dor que levou a maioria das pessoas a reduzir sua capacidade funcional, incluindo as atividades cotidianas como caminhar, correr, praticar esportes e atividade de lazer $22,29,30,33,35$.

Vale destacar que o tempo de tela assistindo à televisão foi a atividade de lazer mais realizada pelos entrevistados, como também ficarem restritos em casa, acessar à internet e ouvir rádio ${ }^{21,29}$. Percebe-se que todas essas atividades podem contribuir para o isolamento social e o tempo de tela excessivo, que termina colaborando para um perfil de inatividade física e sedentarismo, além do mais, esse último pode ser fator de risco para o desenvolvimento de doenças crônicas39. Em geral, as pessoas acometidas por ferida crônica tiveram pior função física e interferência da dor na vida cotidiana ${ }^{22,33,35}$. Todavia o movimento físico foi às vezes evitado ou restringido em decorrência de seu potencial de causar sangramento ou recorrência da ferida ${ }^{22}$.

A rede de apoio foi importante para encorajar as pessoas a procurar assistência de cuidados à saúde e para descoberta da ferida crônica. Todas as faixas etárias foram beneficiadas 
pelo apoio de familiares e amigos, pois eles puderam ajudar a lidar com os medos ${ }^{35}$. O estudo ${ }^{35}$ esclarece que viver com uma ferida crônica significa estar em enfrentamento constante que envolve sentimentos, emoções e estratégias que podem levar à tomada de decisão de procurar um profissional de saúde. É nesse momento, de procura por assistência de cuidados à saúde, que os profissionais precisam oferecer um atendimento integral, ao encontro das circunstâncias mais amplas e singulares das pessoas, que inclua a promoção do bem-estar, qualidade de vida, inclusão social e apoio emocional que possivelmente podem melhorar a adesão terapêutica e estimular efeitos positivos no processo de cicatrização da ferida ${ }^{34}$.

No estudo ${ }^{34}$, a maioria dos entrevistados disse oferecer algum tipo de apoio a outras pessoas que enfrentam a mesma condição crônica, no entanto três deles relataram que a carga de significados e limitações causados pela ferida acabava limitando a sua capacidade de fornecer ajuda emocional. Essa incapacidade de fato foi parcialmente atribuída ao fardo para tentar curar ou impedir recorrências da ferida. Sugere-se que pesquisas futuras estudem alternativas para reduzir as barreiras que existem na relação interpessoal de apoio e no bem-estar emocional, bem como podem tentar incluir intervenções que estimulem o autocuidado e abordagens de autoajuda que sejam planejadas, monitoradas e avaliadas por profissionais capacitados ${ }^{34}$. Pois acredita-se que pode promover a independência, melhorar o bemestar geral e reduzir os custos de cuidados para as pessoas que têm feridas crônicas e para o sistema de saúde ${ }^{7}$. O envolvimento familiar, social e interação com os profissionais de saúde são fundamentais para diminuir as limitações e oportunizar suporte emocional para essas pessoas ${ }^{28}$, pois as relações de confiança e amizade podem contribuir para sua recuperação clínica ${ }^{33}$.

Os entrevistados empregados consideraram o trabalho uma barreira para procurar a assistência de cuidados à saúde devido à priorização do trabalho. Contudo, muitas pessoas falaram que o trabalho era considerado um ambiente de refúgio que dava sentido à vida e ajudava a lidar com a ferida dolorosa ${ }^{35}$. Mas as atividades laborais podem ser prejudicadas pela dor e comprometimento funcional ${ }^{7}$, que muitas vezes ocorreram o afastamento do trabalho em detrimento do tratamento prolongado e da necessidade de se ausentar do serviço para realizar consultas e realização de curativos diários, essas situações terminam gerando repercussões na realidade financeira das pessoas ${ }^{21,33}$.
Os participantes do estudo ${ }^{34}$ disseram que em algumas ocasiões precisaram de ajuda financeira de fontes formais ou informais da sua rede de apoio. Além disso, a aquisição dos dispositivos que auxiliam no tratamento da ferida foi vista como financeiramente inacessíveis pelas pessoas que mais precisavam ${ }^{7,23,33}$. As despesas com o tratamento foram muitas vezes estressantes, posto que interferiram diretamente na estabilidade financeira e no planejamento econômico deles e de seus familiares ${ }^{7}$.

Portanto, os custos demandados pela necessidade de cuidados da ferida ocasionou dependência financeira adicional para os seus familiares e o próprio sistema de saúde $\mathrm{e}^{30,39}$. Essa realidade precisa ser destacada como uma barreira para o

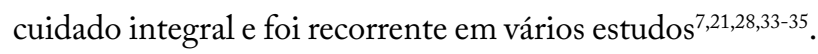
Tentar garantir o desempenho laboral e provimento financeiro para as pessoas adoecidas por feridas favorece certamente $o$ bem-estar, equilíbrio social, possibilidade de continuidade dos cuidados de saúde e colabora para a satisfação com a vida ${ }^{28}$. Observamos também tensões nos relacionamentos íntimos existentes por causa da condição crônica, onde houve um relato de conversas difíceis com os parceiros em virtude da necessidade de sempre precisar se explicar e pedir segredo para o novo companheiro ${ }^{22}$.

Nesse sentido, todos esses fatores contribuíram para o isolamento social em decorrência da carga de significado emocional e das implicações desagradáveis de viver com uma ferida crônica ${ }^{7,21-23,27-35}$. Observa-se, em particular, que um dos motivos do isolamento para as mulheres é o fato de não poderem se vestir conforme desejam, pois passavam a esconder o ferimento com suas roupas para evitar questionamentos ${ }^{28,29,40}$, enquanto os homens acabavam se ausentando das suas atividades físicas e de $\operatorname{lazer}^{19}$. Em outro estudo ${ }^{41}$ as pessoas relataram que evitavam sair de casa devido ao constrangimento de ter sempre alguém observando com curiosidade as suas ataduras. O incômodo da autoimagem aumentava conforme os questionamentos sobre a ferida que os acompanhavam por muito tempo ${ }^{21,28}$. Portanto, destaca-se nesta metassíntese que a ferida crônica tem o potencial de provocar significados profundos sobre a capacidade funcional, social, emocional, financeira e na liberdade para realizar os desejos pessoais.

Os significados de emoções e sentimentos são inerentes à vida e podem influenciar durante o curso do adoecimento ${ }^{35}$. As feridas provocaram nas pessoas a não aceitação da condição clínica frente ao estado de cronicidade da lesão $0^{31,33}$. Sabe-se que a demora da cura pode ser causada pelo déficit 
de conhecimento e falta de cuidados da ferida, assim como pela tentativa de ignorar a condição crônica ${ }^{31}$. A capacidade de aceitação e adaptação dos entrevistados quanto à cronicidade da ferida foi processual ${ }^{28}$. Em outra investigação a aceitação só acontecia quando as pessoas já estavam próximas da cura ${ }^{31}$.

Os entrevistados julgaram como sendo difícil explicar o motivo de suas feridas permanecerem sem cicatrizar e, consequentemente, muitos significados foram expressos, como: preocupações, dor, perda da esperança de cura, diminuição do humor, choro, incapacidade, angústia, medo, raiva, culpa, incômodo, vergonha, insegurança, sentir-se inútil para vida, estresse, sofrimento, aumento da ansiedade, depressão, tentativa de suicídio e luto antecipado ${ }^{7,21-23,27-35}$. A preocupação com a infecção da ferida foi um fator comum entre os entrevistados ${ }^{7}$, pois temiam e se culpavam pelo desenvolvimento de consequências mais graves, como amputação ou morte, o que desencadeava maior instabilidade emocional ${ }^{23,34}$. A amputação é considerada um dos maiores medos das pessoas com feridas, mas também uma alternativa que ocasiona alívio quando a cura da ferida não é possívelel 37,38 Houve um relato de tentativa de suicídio associado à carga emocional e limitações de se viver em um estado de cronicidade, como a interferência da capacidade diminuída de brincar com os filhos ${ }^{20}$.

Em geral, o cotidiano foi significado como irritante, desgastante e que rotineiramente os fazem agir sem paciência, levando-os a agir com agressividade e violência com as pessoas mais próximas da sua rede de apoio, sejam os familiares, amigos e até mesmo os profissionais de saúde. A manifestação da irritabilidade é estimulada principalmente pela não aceitação da ferida ${ }^{28}$. O desespero foi evidenciado principalmente nos momentos em que os profissionais de saúde já haviam tentado diferentes métodos de cuidados e tratamentos associados à percepção deles em relação à demora da cura ${ }^{7}$. Além disso, relataram perda da independência em detrimento da sua mobilidade diminuída, requerendo a inclusão de familiares, parceiros, cuidadores e profissionais de saúde no processo de cuidados básicos, o que gerou sentimentos de angústia, instabilidade emocional e afetou a privacidade devido à necessidade de cuidados íntimos ${ }^{21,30}$.

As pessoas não queriam expor suas preocupações e baixa autoestima, preferiam internalizar seus pensamentos, sentimentos e emoções em vez de compartilhar com sua rede de apoio ${ }^{31,33,34}$. Esse isolamento em razão da condição de bem-estar limitado restringiu os contatos sociais, deixando-os mais sozinhos com seus problemas ${ }^{33}$. Eles sentiram que era difícil conviver com uma ferida que não cicatrizava e quando somado à instabilidade emocional parecia potencializar os sinais depressivos ${ }^{35}$. Confirma-se isso ao analisar o contexto de interações sociais ${ }^{22}$, quando muitas pessoas disseram que sentiam como se estivessem sempre procurando se esconder do mundo por causa da ferida. A soma dos significados de sentimentos e emoções que se envolve no contexto de ter uma ferida crônica acabou contribuindo para o isolamento social ${ }^{28}$, que pode ser ainda mais presente na pessoa idosa ${ }^{35}$.

Em alguns casos, no estudo ${ }^{33}$, o medo aumentou depois da aproximação com os serviços de saúde, normalmente essa aproximação demorava várias semanas ou meses. A rotina das consultas agendadas, encaminhamento para atendimento especializado e os esclarecimentos da equipe de saúde sobre as feridas geraram significados de preocupação. Logo, as pessoas perceberam que haviam tomado decisões precipitadas no início do adoecimento em relação à sua atual condição, que não tinham considerado as feridas como algo preocupante. Para Joaquim et al. ${ }^{33}$, as limitações físicas estão relacionadas aos sinais e sintomas que a ferida crônica provoca, enquanto que os sentimentos e emoções encontram-se associados à condição de viver com a ferida crônica com as demandas de tratamento demorado ou das relações interpessoais e de isolamento.

\section{Desenvolvimento de desejos e estratégias de enfrentamento}

As pessoas desenvolveram significações de diferentes métodos de enfrentamento, que envolviam estratégias para lidar com a ferida dolorosa nos seus corpos, limitações, sentimentos e emoções que pioravam em relação ao tempo de não cura.

Uma das estratégias foi a religiosidade sendo vista como alternativa para tranquilizar o significado da carga emocional e social causada pelas feridas, bem como significou uma fonte de força divina, especialmente quando a rede de apoio familiar ou social era ausente ${ }^{22}$. A espiritualidade significou uma maneira de encontrar conforto e alívio para suportar as demandas de se viver com o corpo ferido e dor ${ }^{33}$. Assim, a associação dos significados da religiosidade e espiritualidade contribuiu para atenuar os pensamentos, sentimentos e emoções negativas e afetou positivamente suas vivências com a condição de dor crônica, além de ajudar na aceitação do 
adoecimento e ser uma fonte de tranquilidade ${ }^{22,28}$. Embora tenha existido um participante que considerou a condição de viver com ferida crônica como um castigo de Deus ${ }^{29}$. A crença divina e esperança na cura motivada pela fé são importantes, mas com o passar do tempo a pessoa pode se tornar descrente devido ao próprio caráter crônico da ferida, que ocasiona a demora da cicatrização e inúmeras recorrências da lesão, que naturalmente leva o indivíduo a ter esperança no fechamento da área da ferida ${ }^{28}$.

Então, recomenda-se que essas pessoas sejam informadas sobre a fisiopatologia da cronicidade da lesão. É importante estimular a construção de redes de apoio como uma estratégia de cuidado, até porque já se sabe que o contexto familiar e os amigos podem fortalecer a vontade das pessoas em ter a iniciativa para procurar ajuda e se submeter aos cuidados e tratamento da ferida ${ }^{35}$.

Quanto aos desejos, os participantes expressaram que são necessárias novas pesquisas para compreender a fisiopatologia da dor marcante nas feridas, mas principalmente desejam que seja encontrada a cura para as feridas dolorosas. Houve também o desejo de que os profissionais médicos passem a compreender os pacientes como pessoas com suas singularidades e não como sintomas da doença ${ }^{22}$. As instituições de pesquisa precisam imediatamente de novas tecnologias para gerenciar e controlar a dor que essas pessoas sentem ou, talvez, se preciso, mudar nossas abordagens sobre a atenuação da dor ${ }^{32}$. Infelizmente ainda é possível a observação da existência de profissionais de saúde que acabam priorizando o modelo de assistência focado na doença e não no indivíduo que necessita de cuidado humano, o conhecimento e práticas de saúde não suportam mais abordagens fragmentadas de cuidado, que concentram suas concepções na doença ${ }^{42}$.É importante oferecer uma assistência humanizada, com acolhimento e respeito aos valores das dimensões humana de um ser carregado de significados de sentimentos e emoções ${ }^{43}$.

O envolvimento interdisciplinar dos campos temáticos dos autores tornou possível incorporar diferentes perspectivas de análise e ampliação da discussão. Acredita-se que este estudo contribui com a literatura qualitativa sobre os significados de se viver com ferida crônica e confirma que as pessoas acometidas por ferida relatam diminuição da capacidade física e funcional, dor insuportável relacionada à ferida, interferência no estilo de vida, isolamento social, instabilidade financeira e diminuição do bem-estar emocional. É pertinente melhorar o gerenciamento e controle da dor, os métodos terapêuticos e a necessidade de intervenções que abordem o estado emocional e clínico dessas pessoas, como também o desenvolvimento de ações de educação em saúde para elas, seus familiares e cuidadores, além da necessidade de divulgar para a sociedade informações sobre os diferentes aspectos de se viver com uma ferida crônica. É importante um empenho contínuo dos profissionais de saúde que cuidam de feridas para diminuir os efeitos negativos provocados pelas feridas crônicas ${ }^{44}$.

Existem limitações nesta metassíntese que precisam ser pontuadas. Em relação à tradução dos artigos, pois foram encontradas dificuldades na compreensão de alguns relatos dos entrevistados relacionadas ao idioma e às questões culturais do país. Além disso, foram valorizados os achados de acordo com a maior frequência de apresentação nos estudos, principalmente em virtude da maneira como foram realizadas a extração e análise dos resultados do estudo original. Outra possível limitação foi quanto à consolidação dos estudos de diferentes perspectivas de análise e óticas filosóficas, como também da decisão de incluir estudos independentemente do tipo de ferida. Levando em conta essas limitações, pode-se assumir que houve significados de experiências semelhantes entre as pessoas que viviam com ferida crônica nos estudos selecionados independentemente do tipo de ferida, como visto em outros estudos ${ }^{7,41}$.

\section{CONCLUSÃO}

Viver com uma ferida crônica significa experimentar enfrentamento emocional constante, que começa com preocupações iniciais, aparecimento dos sintomas, principalmente a dor de característica marcante, procura por informações e assistência à saúde, mudança na relação interpessoal, que inclui o convívio familiar e social, instabilidade financeira e manifestações de tristeza, choro, incapacidade, angústia, medo, raiva, culpa, incômodo, vergonha, insegurança, sentimento de inutilidade para a vida, estresse, sofrimento, aumento da ansiedade, depressão, tentativa de suicídio e luto antecipado. A dor crônica e a carga dos significados da esfera emocional isolam a pessoa do mundo externo e a aprisionam dentro do seu próprio corpo ferido.

As estratégias de enfrentamento receberam significado de refúgio, tranquilidade e alívio durante o curso de adoecimento e estão embasadas na religiosidade e espiritualidade, que acabou motivando a esperança de cura nas pessoas. A rede de 
apoio de familiares, amigos e colegas de trabalho significou estímulo para a pessoa aceitar a cronicidade da ferida e buscar assistência de cuidados a saúde. Os achados aqui apresentados podem auxiliar em condutas para o cuidado clínico e desenvolvimento de novos estudos e tecnologias, especialmente para o gerenciamento e controle da dor, redução do tempo de cicatrização da ferida e diminuição do isolamento social.

\section{CONTRIBUIÇÃO DOS AUTORES}

\author{
Conceitualização: Araújo WA e Assis WC; Metodologia:
} Araújo WA, Assis WC e Rocha RM; Investigação: Araújo WA, Assis WC e Rocha RM; Redação - Primeira versão: Araújo WA e Assis WC; Redação - Revisão \&Edição: Araújo WA, Assis WC, Vilela ABA, Boery RNSO, Rodrigues VP e Rocha RM; Supervisão: Rocha RM.

\section{REFERÊNCIAS}

1. Fearns N, Heller-Murphy S, Kelly J, Harbour J. Placing the patient at the centre of chronic wound care: a qualitative evidence synthesis. J of Tissue Viability 2017;26(4):254-9. https://doi.org/10.1016/j.jtv.2017.09.002

2. Gupta S, Andersen C, Black J, Leon J, Fife C, Lantis li JC et al. Management of chronic wounds: diagnosis, preparation, treatment, and follow-up. Wounds: a compendium of clinical research and practice. 2017 Sep; [citado 2019 ago 12]; 29(9):S19-S36. Disponível em: https://europepmc.org/ article/med/28862980

3. Lentsck MH, Baratieri T, Trincaus MR, Mattei AP, Miyahara CTS. Qualidade de vida relacionada a aspectos clínicos em pessoas com ferida crônica. Rev Esc Enferm USP 2018;52:e03384. https://doi.org/10.1590/s1980-220×2017004003384

4. Hopman WM, Buchanan M, VanDenKerkhof EG, Harrison MB. Pain and health-related quality of life in people with chronic leg ulcers. Chronic Diseases and Injuries in Canada. 2013; [citado 2019 ago 13]; 33(3):167-74. Disponível em: https://europepmc.org/article/med/23735456

5. Joaquim FL, Camacho ACLF, Silva RMCRA, Leite BS, Queiroz RS, Assis CRC. Impact of home visits on the functional capacity of patients with venous ulcers. Rev Bras Enferm 2017 Mar/Apr;70(2):287-93. https://doi.org/10.1590/00347167-2016-0291

6. Renner R, Erfurt-Berge C. Depression and quality of life in patients with chronic wounds: ways to measure their influence and their effect on daily life. Chronic Wound Care Manag Res 2017;4:143-51. https://doi.org/10.2147/CWCMR. S124917

7. Kapp S, Miller C, Santamaria N. The quality of life of people who have chronic wounds and who self-treat. J Clin Nurs 2018 Jan;27(1-2):182-92. https://doi.org/10.1111/jocn.13870

8. Stewart A, Edwards H, Finlayson K. Reflection on the cause and avoidance of recurrent venous leg ulcers: an interpretive descriptive approach. J Clinical Nurs 2018 Mar;27(5-6):e931-e9. https://doi.org/10.1111/jocn.13994

9. Khunkaew S, Tungpunkom P, Sim J, Fernandez RS. The experiences of people in northern Thailand living with diabetic foot ulcers: a descriptive qualitative study. Pacific
Rim International Journal of Nursing Research. 2018; [citado 2020 jun 23]; 22(4):304-18. Disponível em: https://ro.uow. edu.au/smhpapers1/260/

10. Brown A. Chronic leg ulcers, part 2: do they affect a patient's social life?. Br J Nurs 2005 Oct;14(18):986-9. https://doi. org/10.12968/bjon.2005.14.18.19888

11. Probst $S$, Séchaud $L$, Bobbink $P$, Skinner MB, Weller CD. The lived experience of recurrence prevention in patients with venous leg ulcers: an interpretative phenomenological study. J Tissue Viability 2020 Aug;29(3):176-9. https://doi. org/10.1016/j.jtv.2020.01.001

12. Waidman MAP, Rocha SC, Correa JL, Brischiliari A, Marcon SS. O cotidiano do indivíduo com ferida crônica e sua saúde mental. Texto Contexto-Enferm 2011 out/dez;20(4):691-9. https://doi.org/10.1590/S0104-07072011000400007

13. Briggs $M$, Flemming K. Living with leg ulceration: a synthesis of qualitative research. J Adv Nurs 2007 Aug;59(4):319-28. https://doi.org/10.1111/j.1365-2648.2007.04348.x

14. Phillips P, Lumley E, Duncan R, Aber A, Woods HB, Jones GL et al. A systematic review of qualitative research into people's experiences of living with venous leg ulcers. J Adv Nurs 2018 Mar;74(3):550-63. https://doi.org/10.1111/jan.13465

15. Gomes E, Donoso MTV, Werli-Alvarenga A, Goveia VR. Compreendendo os significados de se conviver com ferida crônica. Rev Enferm Atenção Saúde 2018 ago/set;7(2):17688. https://doi.org/10.18554/reas.v7i2.2396

16. Campbell R, Pound P, Morgan M, Daker-White G, Britten N, Pill R et al. Evaluating meta-ethnography: systematic analysis and synthesis of qualitative research. Health Technol Assess 2011 Dec;15(43):1-164. https://doi.org/10.3310/hta15430

17. Sandelowski M, Barroso J. Handbook for Synthesizing Qualitative Research. New York: Springer Publishing Company; 2007. p.284.

18. Joanna Briggs Institute. Joanna Briggs Institute reviewers' manual: 2008 edition. Adelaide; 2008.

19. Moher D, Liberati A, Tetzlaff J, Altman DG, PRISMA Group. Preferred reporting items for systematic reviews and metaanalyses: the PRISMA statement. Ann Intern Med 2009 
Aug;151(4):264-9. https://doi.org/10.7326/0003-4819-1514-200908180-00135

20. Vieira AJ, Garrett JM. Understanding interobserver agreement: the Kappa statistic. Family Medicine. 2005; [citado 2019 jun 03]; 37(5):360-3. Disponível em: http:// www.stfm.org/fmhub/fm2005/May/Anthony360.pdf

21. Jackson DE, Durrant LA, Hutchinson M, Ballard CA, Neville $S$, Usher K. Living with multiple losses: insights from patients living with pressure injury. Collegian 2018;25(4):409-14. https://doi.org/10.1016/j.colegn.2017.10.008

22. Umeh NI, Ajegba B, Buscetta AJ, Abdallah KE, Minniti CP, Bonham VL. The psychosocial impact of leg ulcers in patients with sickle cell disease: i don't want them to know my little secret. PloS One 2017 Oct;12(10):e0186270. https://doi. org/10.1371/journal.pone.0186270

23. Barg FK, Cronholm PF, Easley EE, Davis T, Hampton M, Malay DS et al. A qualitative study of the experience of lower extremity wounds and amputations among people with diabetes in Philadelphia. Wound Repair Regen 2017 Sep;25(5):864-70. https://doi.org/10.1111/wrr.12593

24. Critical Appraisal Skills Programme. CASP Qualitative Research checklist. 2013 [citado 2019 jun 03]. Disponível em: https://casp-uk.net/wp-content/uploads/2018/03/ CASP-Qualitative-Checklist-2018_fillable_form.pdf

25. Tong A, Flemming K, Mclnnes E, Oliver S, Craig J. Enhancing transparency in reporting the synthesis of qualitative research: ENTREQ. BMC Med Res Methodol 2012;12(1):181. https://doi.org/10.1186/1471-2288-12-181

26. Braun V, Clarke V. Using thematic analysis in psychology. Qualitative Research in Psychology. 2006; [citado 2019 jun 06]; 3(2):77-101. Disponível em: https://www.tandfonline. com/doi/abs/10.1191/1478088706qp063oa

27. Aguiar ACSA, Amaral L, Reis LA, Barbosa TSM, Camargo CL, Alves MR. Changes in the lifestyle of people with venous ulcer. Revista Cubana de Enfermería. 2014; [citado 2019 jun 09]; 30(3). Disponível em: http://www.revenfermeria.sld.cu/ index.php/enf/article/view/510/98

28. Alves RM, Carvalho ESS, Santos LM, OliveiraJF, Araújo EM. Ser mulher e ter o corpo ferido: um estudo de representações sociais. Rev Pesqui 2014 out/dez;6(4):1513-24. https://doi. org/10.9789/2175-5361.2014.v6i4.1513-1524

29. Alves JF, Sousa ATO, Soares MJGO. Sentimentos de inclusão social de pessoas com úlcera venosa. Rev Enferm UFSM 2015 abr/jun;5(2):193-203. https://doi. org/10.5902/2179769215425

30. Buso ALZ, Mendonça FTNF, Nunes JS, Ferreira LA, Santos ÁS, Zuffi FB. Perceptions of elderly living with leg ulcer. Biosci J 2016 Sep/Oct;32(5):1373-9. https://doi.org/10.14393/BJv32n1a2016-32738

31. Cipolletta S, Amicucci L. Illness trajectories in patients suffering from leg ulcers: a qualitative study. J Health Psychol 2017 Jun;22(7):932-42. https://doi. org/10.1177/1359105315619224
32. Lernevall LSD, Fogh K, Nielsen CB, Dam W, Dreyer PS. Lived experiences of life with a leg ulcer-a life in hell. EWMA Journal. 2017;17(1):15-21.

33. Joaquim FL, Silva RMCRA, Pereira ER, Garcia-Caro MP, CruzQuintana F. Application of Merleau-Pontyan perspective on the physical and psychological implications of venous ulcers. Rev Bras Enferm 2018 Sep/Oct;71(5):2469-76. http://doi. org/10.1590/0034-7167-2017-0542

34. Palaya J, Pearson S, Nash T. Perception of social support in individuals living with a diabetic foot: a qualitative study. Diabetes Res Clin Pract 2018 Dec;146:267-77. https://doi. org/10.1016/j.diabres.2018.10.016

35. Marczak J, Rembeck G, Petersson E-L, Nordeman L. Patient experiences of living with chronic leg ulcers and making the decision to seek professional health-care. J Wound Care 2019 Jan;28(Sup1):S18-S25. https://doi.org/10.12968/ jowc.2019.28.Sup1.S18

36. Taverner T, Closs J, Briggs M. A meta-synthesis of research on leg ulceration and neuropathic pain. $\mathrm{Br} J$ Nurs 2011;20(Sup12):S18-S27. https://doi.org/10.12968/ bjon.2011.20.Sup12.S18

37. Cwajda-Bialasik J, Szewczyk MT, Mościcka P, Cierzniakowska $\mathrm{K}$. The locus of pain control in patients with lower limb ulcerations. J Clin Nurs 2012;21(23-24):3346-51. https://doi. org/10.1111/j.1365-2702.2012.04163.x

38. Taverner T, Closs SJ, Briggs M. The journey to chronic pain: a grounded theory of olderadults' experiences of pain associated with leg ulceration. Pain Manag Nurs 2014 Mar;15(1):186-98. https://doi.org/10.1016/j.pmn.2012.08.002

39. Ussery EN, Fulton JE, Galuska DA, Katzmarzyk PT, Carlson SA. Joint prevalence of sitting time and leisure-time physical activity among US adults, 2015-2016. Jama. 2018;320(19):2036-38. https://doi.org/10.1001/jama.2018.17797

40. Souza MKB, Matos IAT. Percepção do portador de ferida crônica sobre sua sexualidade. 2010; 18(1):19-24.

41. O'Brien J, Finlayson K, Kerr G, Edwards H. The perspectives of adults with venous leg ulcers on exercise: an exploratory study. J Wound Care 2014 Oct;23(10):496-509. https://doi. org/10.12968/jowc.2014.23.10.496

42. Waidman MAP, Rocha SC, Correa JL, Brischiliari A, Marcon SS. O cotidiano do indivíduo com ferida crônica e sua saúde mental. Texto contexto-Enferm 2011 out/dez;20(4):691-9. https://doi.org/10.1590/S0104-07072011000400007

43. Hecke AV, Verhaeghe S, Grypdonck M, Beele H, Defloor T. Processes underlying adherence to leg ulcer treatment: a qualitative field study. Int J Nurs Stud 2011 Feb;48(2):145-55. https://doi.org/10.1016/j.ijnurstu.2010.07.001

44. Turk DC, Fillingim RB, Ohrbach R, Patel KV. Assessment of psychosocial and functional impact of chronic pain. J Pain 2016;17(9):T21-T49. https://doi.org/10.1016/j.jpain.2016.02.006 